Crítica de poesia II 



\title{
Manoel de Barros: em que acreditar senão no riso? ${ }^{1}$
}

\author{
Alberto PuCheU ${ }^{I}$
}

$\mathrm{E}$

M 1989, com a publicação da revista Bric-a-Brac, li pela primeira vez Manoel de Barros. Na entrevista, que não fora oral, mas, como todas até certo ponto de sua vida, por escrito, Manoel de Barros reinventava os modos da entrevista e da poesia: a primeira era a continuação da segunda, e nesta uma gramática como a Língua Portuguesa não havia escutado se fazia na construção de frases inteiramente inesperadas. Criava-se ali, ou pelo menos ali se radicalizava ao extremo, um novo gênero: o das entrevistas (poéticas) por escrito, que Manoel de Barros soube explorar como nenhum outro escritor, levando-o a um pensamento inteiramente singular.

Nesse desejo de tornar a entrevista mais uma possibilidade poética, Manoel de Barros se colocava publicamente todo o tempo como escritor. Não à toa, logo no início da entrevista, mal ela tenha sido começada, ele declarava: "Bom, mas isso já é Literatura”. Sim, isso, a entrevista, desde seu começo, já é literatura, já é poesia, já é escrita, e essas, tanto faz o nome que privilegiemos, já são a constituição de um escapar, pelas frinchas, para criar em si um "aparelho de ser inútil”. Temos aqui uma definição provisória do que é ser poeta: “em quem não presta para nada” (em quem, quando menino, "não gostava de estudar”, era “abúlico", "amorfo", "vivia-se esgueirando"), o escape pela feitura, através de um dom, de um "aparelho de ser inútil".

Se lembrarmos que ele estudava em um internato de padres e, consequentemente, a filosofia e o pensamento eram integralmente comprometidos com o ensino religioso, fica fácil entender a negativa que precede a afirmação de como vê o poeta enquanto "aparelho de ser inútil":

Eu não gostava de refletir, de filosofar; mas os desvios linguísticos, os volteios sintáticos, os erros praticados para enfeitar frases, os coices na gramática dados por Camilo, Vieira, Camões, Bernardes - me empolgavam. Ah, eu prestava era praquilo! Eu queria era aprender a desobedecer na escrita.

Esse trabalho de desobediência do poeta, entendido enquanto "um aparelho de ser inútil", pelo fazer da escrita resultante de um dom, se dá na construção material da frase desse que, por não se adequar, precisa escapar, mesmo que andando contraproducentemente de costas, encontrando, na fuga, a poesia.

Antes de ser pontual contra uma ou outra regra, a desobediência do poeta é intensiva, abrangendo tudo, pois a ambiência na qual ele vive é 
[...] uma fonte de escuros. Coisas se movendo ainda em larvas, antes de ser ideia ou pensamento. É nessa área do instinto que o poeta está. A coisa ainda particular, corporal, ainda não generalizada e nem mentada. Aquilo que mestre Aristóteles falou: "Todo conhecimento passa antes pelos sentidos". $\mathrm{O}$ poeta é o primeiro a tocar nos ínfimos. Nas pré-coisas.

Antes das ideias e pensamentos, na pura imanência, passando pelos sentidos de modo a, impulsionado também por Rimbaud, desregrá-los imensamente, falar o larval das coisas, seus ínfimos, "as coisas ainda inominadas. Como no começo dos tempos", as pré-coisas, como já havia intitulado um de seus livros e como escreverá em $O$ guardador de águas:

Nas Metamorfoses, em duzentas e quarenta fábulas,

Ovídio mostra seres humanos transformados em

pedras, vegetais, bichos, coisas.

Um novo estágio seria que os entes já transformados falassem um

dialeto coisal, larval, pedral etc. Nasceria uma linguagem

madruguenta, adâmica, edênica, inaugural -

Que os poetas aprenderiam - desde que voltassem às crianças que foram

Às rãs que foram

Às pedras que foram.

Para voltar à infância, os poetas precisariam também de reaprender

a errar a língua.

Esse larval, "esses começos de coisas / indistintas", estava anteriormente explicitado em O livro de pré-coisas, de 1985. No encontro com o pré das coisas, com a antecoisa, com o larval, ao descobrir que queria apenas se ser nas coisas, como escreve, portanto, o poeta, como se dá a desconstrução e reconstrução material mesma da gramática das frases do poeta entendido enquanto "o aparelho de ser inútil" em sua desobediência generalizada diante do desregramento dos sentidos (dos seus sentidos e dos sentidos da linguagem) em busca do "dialeto coisal, larval, pedral" dessa "linguagem madruguenta, adâmica, edênica, inaugural"? A gramática de Manoel de Barros é uma agramática que, perturbando a ordem gramatical, dá "coices na gramática" em busca de dizer o inominado das coisas e o inominado da linguagem enquanto inominado que se preserva no dito, na medida em que "palavras que normalmente se rejeitam, eu caso, eu himeneio".

Sendo capaz de orientar seus descaminhos sem que deles possa se esquivar e de dizer obsessivamente que, não servindo para nada, muito menos para a comunicação, a linguagem dessa agramática, tal como construída pelo "aparelho de ser inútil" em exercício de sua desobediência, diz coisas que existem apenas na poesia, como: "Agosto estava por um trevo", ou "Lagarto escuma verde antes de foder", "lagartixas piscam para as moscas antes de havê-las", ou "andar perante corgos abre arpejos", "o osso de uma fala minada de harpas", "um útero de lanhos brancos", "um canteiro de vermes estrábicos", "o erotismo do chão se enraíza na boca", "a garça aguça o pescoço para ouvir os perfumes do arroio", 
"um beija-flor de rodas vermelhas", "Quando chove nos braços da formiga o horizonte diminui", "formiga não tem dor nas costas", "besouros não trepam no abstrato"... Como tais elementos díspares se juntam ao mesmo tempo em cada frase desse que fala de maneira "desmendada"? Que relações tensivas e insolúveis são essas entre tais momentos em atrito de cada frase?

Para Manoel de Barros, enquanto a produção, propiciada por um dom, de um aparelho de ser inútil em quem não presta para mais nada na vida, o poeta escapa através de um trabalho de desregramento do corpo, colocado em fusão com as coisas, e de desobediência intensiva dos sentidos da língua. Essa desobediência atua diretamente na reconstrução material da frase, gerando uma agramaticalidade que, perturbando a ordem, busca dizer o inominado, o larval, os ínfimos das coisas, as pré- ou antecoisas e o inominado da linguagem. Com o inominado que, enquanto inominado, se preserva no dito dando a ver o puro ter lugar da linguagem em sua potência não representativa, o primeiro poema de O guardador de águas mostra a que o respectivo livro vem:

O aparelho de ser inútil estava jogado no chão, quase

coberto de limos -

Entram coaxos por ele dentro.

Crescem jacintos sobre palavras.

(O rio funciona atrás de um jacinto.)

Correm águas agradecidas sobre latas...

O som do novilúnio sobre as latas será plano.

E o cheiro azul do escaravelho, tátil.

De pulo em pulo um ente abeira as pedras.

Tem um cago de ave no chapéu.

Seria um idiota de estrada?

Urubus se ajoelham pra ele.

Luar tem gula de seus trapos.

A primeira parte do livro é homônima ao título geral. Nela, quinze poemas se sucedem em série, numerados e submetidos ao título da parte e do livro como um todo. Salta à vista a presença não apenas do poeta denominado como "o aparelho de ser inútil", mas, igualmente, de personagens - fato raro, aliás, na poesia - muito singulares como Bernardo (ou Bernardão ou Bernardo da Mata, que, desde sua aparição em O livro de pré-coisas, se torna o mais recorrente em seus poemas) e Roupa-Grande; mais adiante no mesmo livro aparecerá Seu França, que "não presta para nada", que "Disse que precisa de não ser ninguém toda vida. / De ser o nada desenvolvido / E disse que o artista tem origem nesse ato suicida". ${ }^{2}$ Ao poeta entendido como "o aparelho de ser inútil" e a esses apelidados de Bernardo da Mata e Roupa-Grande juntam-se, apenas na primeira parte do livro, os "idiotas da estrada", os "tontos", os "viventes do ermo", os "donos de nadifúndios", os "estafermos", os "entretontos", que se dizem uns pelos outros... Esses entes conversam com águas, são coalescentes às coisas, aperfeiçoados pelo nada, têm vozes batráquias, criam peixes nos bolsos, vivem, 
enfim, “- A partir da fusão com a natureza”, pela qual "se tornaram eróticos. Se encostavam no corpo da natureza para/ exercê-la. E se tornavam apêndices dela. / Ou seres adoecidos de natureza".

É certo que, aparecendo misturados, esses personagens são entendidos como uma espécie de heterônimos do poeta, de seus alter egos, como ele mesmo diz no poema "A borra", de outros nomes que para ele podem ser dados de outras vidas pelas quais o poeta se diz, já que parecem se colocar do mesmo modo em sua fusão erótica com a natureza, em sua coalescência com o corpo do mundo. Se o poema mostrado, o primeiro do livro, fala do poeta enquanto "o aparelho de ser inútil", no décimo primeiro verso desse poema constituído por treze versos, é por uma pergunta, entretanto, que o poeta se vincula aos "idiotas da estrada": "Seria ["o aparelho de ser inútil"] um idiota da estrada?". É uma pergunta de difícil resposta, sobretudo, porque nosso impulso imediato, corroborado pelo modo como o poeta é apresentado no poema em questão, é responder afirmativamente a ela, como se confirmássemos que, sim, o poeta é "um idiota da estrada", e isso bastasse.

A se responder afirmativamente tal pergunta, será necessário, primeiro, atravessá-la em sua dificuldade. Há um poema tardio da série que causa um problema a tal aquiescência apressada. Digo tardio porque ele não se encontra na primeira edição, publicada pela Art Editora, de São Paulo, em 1989; é em Gramática expositiva do chão (poesia quase toda), do ano seguinte, que o poema número X da primeira edição é deslocado para adiante, para o segundo lugar da terceira série do livro, "Seis ou treze coisas que eu aprendi sozinho", dando, a partir daí, em todas as coletâneas subsequentes, seu lugar a um poema até então inédito, exatamente esse a que agora me refiro. Esse é sobre um "estafermo", ironicamente tratado de "o mais engenhoso estafermo", o mais estafermo dos estafermos, o que, contraditoriamente, mais engenho tem na arte vital de ser estafermo, palavra que traz para seu campo de compreensão os sentidos de pessoa parada, embasbacada, sem préstimo, mal-ajambrada, de mau aspecto, inútil. Com sua inutilidade assegurada, o estafermo se relaciona, sem dúvida, com o "aparelho de ser inútil" que é o poeta, mas não é completamente identificado a ele; em sua sintaxe enigmática, o poema termina com os versos: "Esse homem / Teria, sim / O que um poeta falta para árvore".

Em sua agramaticalidade, que "[...] desarruma os vocábulos [...] / E os deixa em lanhos na beira da voz" já que "O sentido normal das palavras não faz bem ao poema", tratando-se de "Escurecer as relações entre os termos em vez de aclará-los" para que se "empoem[e] o sentido das palavras" em "um inauguramento de falas", o último verso é de grande complexidade gramatical, levando-nos, primeiramente, a uma facilitação para melhor clarificar uma leitura possível de seu erro proposital: esse homem teria, sim, o que [a][em] um poeta falta para [ser] [chegar a] árvore. Nesse sentido, o estafermo estaria em um grau mais privilegiado que o poeta, pois teria o que falta a um poeta para se tornar 
plenamente coisal. Se a preposição (a ou em) não é colocada, parece ser para evitar tornar o poeta um sujeito "dentro" do qual algo acontece; em busca do coisal do homem, em busca do poeta enquanto "um homem que entrara na prática do limo" ou como um "homem de lata” ou como um "promíscuo dos bichos, dos vegetais, das pedras", em busca da fusão da superficialidade de seu corpo com o corpo da natureza e do mundo, Manoel de Barros cria variações linguísticas constantes para evitar que o homem compareça como um sujeito autônomo que se opõe a um objeto qualquer (lembro-me, só para dar um exemplo, do magnífico verso: “as paisagens comiam no meu olho”). Na retirada da preposição que eleva o grau de agramaticalidade da frase, no erro proposital de sua gramática, o poeta se encontra encaminhado em sua fusibilidade com a árvore, ainda que, nesse poema especificamente, em comparação ao estafermo, não cumprida de modo integral. É certo que, nessa poética, a falta se confunde com o homem permitindo-o a se tornar coisal, como dito no livro Matéria de poesia, no qual tanto “A gente é rascunho de pássaro / Não acabaram de fazer” quanto "Um idiota de estrada passava por árvore".

Por aquele poema de número $\mathrm{X}$, inserido tardiamente à série, à pergunta do que abre o livro, "Seria ["o aparelho de ser inútil"] um idiota da estrada?", a resposta me pareceria ser: não, “o aparelho de ser inútil” não é um idiota da estrada. Esse privilégio dos personagens e dos idiotas da estrada em relação ao poeta é compreensível, como uma homenagem às pessoas com quem o poeta aprende aquilo que lhe interessa em sua poesia. Sabe-se que Manoel de Barros reluta nas entrevistas em chamar seus personagens de seus heterônimos, sem negar nem aceitar completamente tal colocação, ou aceitando-a e negando-a, em titubeio, ao mesmo tempo. Os personagens criados por Manoel de Barros se constituem como outros eus, paradigmáticos ou exemplares, do poeta, que, se encontrando com ele pelo mundo, o impulsionam ainda mais para fora de si no movimento de se tornar coisal, fundido à natureza.

No poema I, entretanto, enquanto “aparelho de ser inútil”, o poeta está, em sua coisalidade superficial, completamente fundido ao corpo da natureza, levando-nos à indiscernibilidade entre poetas e "idiotas da estrada", como afirma um poema de outra série do livro: "Poetas e tontos se compõem com palavras". Enquanto no livro seguinte, o poeta dirá que "(Penso que o rio me aprimorava)" e, mais diretamente da relação entre o poeta e os "idiotas da estrada", que "Naqueles relentos de pedra e lagartos, gostava de conversar com/ idiotas de estrada e maluquinhos de mosca" sendo certo que com eles "Ali me anonimei de árvore", em Oguardador de águas, onde está o poema em que "o aparelho de ser inútil" é nomeado, em outro poema que se refere aparentemente ao poeta, é afirmado que ele (supostamente, o poeta) "Um dia chegou em casa árvore". "Esse homem / Teria, sim / O que um poeta falta para árvore".

Nesse sentido, agora, talvez estejamos aptos a aceitar o fato poético de o poeta ser como os idiotas da estrada, vivendo como eles, como tão bem mostra 
o poema número I de Oguardador de águas, um dos, para mim, insuperáveis da poesia brasileira. Ei-lo, o poema, mais uma vez:

O aparelho de ser inútil estava jogado no chão, quase

coberto de limos -

Entram coaxos por ele dentro.

Crescem jacintos sobre palavras.

(O rio funciona atrás de um jacinto.)

Correm águas agradecidas sobre latas...

O som do novilúnio sobre as latas será plano.

E o cheiro azul do escaravelho, tátil.

De pulo em pulo um ente abeira as pedras.

Tem um cago de ave no chapéu.

Seria um idiota de estrada?

Urubus se ajoelham pra ele.

Luar tem gula de seus trapos.

Ainda podemos sinalizar que um livro tardio do poeta, de 1998, Retrato do artista quando coisa, estende, desviando Joyce, essa dimensão do poeta enquanto coisal.

Se tanto na entrevista quanto em Oguardador de águas, ambos de 1989, há uma singular posição do poeta entendido enquanto "o aparelho de ser inútil", é no livro de 1980, Arranjos para assobio, que Manoel de Barros havia, antes, estabelecido o conceito de inútil e suas derivações como modo de pensar a poesia: Só me preocupo com as coisas inúteis, "O poema é antes de tudo um inutensílio", um dos "bens do poeta" é "um fazedor de inutensílios", o bugre Aniceto traz consigo sete inutensílios e no título do respectivo poema, Sete inutensílios de Aniceto, há uma nota de pé de página duplamente irônica: primeiramente, por usar, nos poemas, como havia antes feito em Gramática expositiva do chão, notas de pé de páginas, que são mecanismos de um discurso técnico-científico-acadêmico do qual seus poemas querem se afastar, como em todo elogio ao que tem "soberba desimportância científica"; depois, por, na nota, atrelar os “inutensílios", além de à tradição indígena brasileira, aos mais variados tempos da alta tradição poética ocidental ("Estes inutensílios foram colhidos entre os Mitos Cadiuéus, narrados pelo professor Darcy Ribeiro. Resguardando-se petulância e distância, exercitou-se aqui a moda posta em prática por Eliot, incorporando à sua obra versos de Shakespeare, Dante, Baudelaire. E o que fez um pouco James Joyce aproveitando-se de Homero. E ainda o que fez Homero aproveitando-se dos rapsodos gregos. / Ai pobres Cadoveos! Esse bugre Aniceto aí de cima é que vai perpetuar vocês? Nem xum. (N. do A. ))".

Se em tal percurso a poesia passou a ser entendida enquanto "fazer coisas desúteis", descobrindo, nas coisas, suas “desutilidade[s] poética[s]", o que nelas serve para "o desuso pessoal de cada um”, no livro Matéria de poesia, de 1970, encontra-se um poema, o primeiro do livro, que, sem ainda usar tais termos, já traz em si tal compreensão de que servem para poesia "todas as coisas cujos 
valores podem ser / disputados no cuspe a distância", "as coisas que não levam a nada", "cada coisa ordinária", "cada coisa sem préstimo", "tudo aquilo que nos leva a coisa nenhuma / e que você não pode vender no mercado", "tudo aquilo que a nossa / civilização rejeita, pisa e mija em cima", "pessoas desimportantes", "as coisas jogadas fora", "como um homem jogado fora", "as coisas sem importância"... Ainda que longa, deixemos a primeira parte desse poema também serial soar:

Todas as coisas cujos valores podem ser

disputados no cuspe a distância

servem para a poesia

O homem que possui um pente

e uma árvore

serve para poesia

Terreno de $10^{\circ}-20$, sujo de mato - os que

nele gorjeiam: detritos semoventes, latas

servem para poesia

Um chevrolé gosmento

Coleção de besouros abstêmios

O bule de Braque sem boca

são bons para poesia

As coisas que não levam a nada

têm grande importância

Cada coisa ordinária é um elemento de estima

Cada coisa sem préstimo

tem seu lugar

na poesia ou na geral

O que se encontra em ninho de joão-ferreira:

caco de vidro,

garampos,

retratos de formatura,

servem demais para poesia

As coisas que não pretendem, como

por exemplo: pedras que cheiram

água, homens

que atravessam períodos de árvore,

se prestam para poesia

Tudo aquilo que nos leva a coisa nenhuma

e que você não pode vender no mercado 
como, por exemplo, o coração verde

dos pássaros,

serve para poesia

As coisas que os líquenes comem

- sapatos, adjetivos -

têm muita importância para os pulmões

da poesia

Tudo aquilo que a nossa

civilização rejeita, pisa e mija em cima, serve para poesia

Os loucos de água e estandarte

servem demais

O traste é ótimo

O pobre-diabo é colosso

Tudo que explique

o alicate cremoso

e o lodo das estrelas

serve demais da conta

Pessoas desimportantes

dão pra poesia

qualquer pessoa ou escada

Tudo que explique

a lagartixa de esteira

e a laminação de sabiás

é muito importante para a poesia

O que é bom para o lixo é bom para poesia

Importante sobremaneira é a palavra repositório;

a palavra repositório eu conheço bem:

tem muitas repercussões

como um algibe entupido de silêncio

sabe a destroços

As coisas jogadas fora

têm grande importância

- como um homem jogado fora

Aliás, é também objeto de poesia

saber qual o período médio

que um homem jogado fora 
pode permanecer na terra sem nascerem

em sua boca as raízes da escória

As coisa sem importância são bens de poesia

Pois é assim que um chevrolé gosmento chega

ao poema e as andorinhas de junho.

Sabe-se que Paulo Leminski publicou um ensaio intitulado $A$ arte e outros inutensílios no dia 18.10.1986, no caderno "Ilustrada" da Folha de S.Paulo, buscando estabelecer um pensamento "da arte como inutensílio" para além ou para aquém da mercadoria e do lucro, como resistência a eles. Depois de dizer que "Coisas inúteis (ou in-úteis) são a própria finalidade da vida", salientando que a poesia não serve para nada, chegando ao fim do texto, sua formulação ganha os melhores contornos: “A rebeldia é um bem absoluto. Sua manifestação na linguagem, nós, homens, chamamos poesia, inestimável inutensílio”. Longe de mim propor aqui uma interpretação desse conceito de Leminski, até porque pesquisadores do poeta frequentemente trabalham sua compreensão da poesia como inutensílio, mas me cabe assinalar que nenhum de seus comentadores chama atenção para o fato de que o termo surge antes em Manoel de Barros, em 1980. Como salientei anteriormente, antecedendo o texto leminskiano em seis anos, em Arranjos para assobio, está escrito que "O poema é antes de tudo um inutensílio" e que entre os bens do poeta está “um fazedor de inutensílios”.

Para que não se caia em uma contraposição fácil entre um Leminski urbano, político e crítico do "lucrocentrismo" em diferença a um Manoel de Barros de uma poética exclusiva da natureza (entendida, em geral, de modo precário), repito a passagem presente em "Matéria de poesia", de 1970:

Tudo aquilo que nos leva a coisa nenhuma

e que você não pode vender no mercado

como, por exemplo, o coração verde

dos pássaros,

serve para poesia $[\ldots]$ tudo aquilo que a nossa

civilização rejeita, pisa e mija em cima,

serve para a poesia

[...] Pessoas desimportantes

dão para a poesia

qualquer pessoa ou escada

[...] o que é bom para o lixo é bom para a poesia.

E quanto à "rebeldia" defendida por Leminski, lembro a "desobediência" e o aspecto de fusão do corpo com o mundo mostrados desde o começo dessa apresentação. Certamente, ainda falta uma leitura política dos poemas de Manoel de Barros. Até onde sei, o vídeo em que Leminski fala do "inutensílio" e os outros textos que, implícita ou explicitamente, abordam o mesmo termo são de 1985 ou 1986. Teria sido o uso por Leminski do conceito presente antes em 
Manoel de Barros uma mera coincidência? Teria sido Leminski um leitor de Manoel de Barros quando este ainda era pouquíssimo lido? Leminski vinha fazendo um uso velado de tal conceito antes do momento em que o trouxe a público? Tais questões sobreviverão a nossa conversa; que elas fiquem como instigação a pesquisas futuras dos muitos especialistas em Leminski.

Foi em 1990 que a Civilização Brasileira, com seu editor Ênio da Silveira, lançou um livro que será um marco na poesia brasileira: Gramática expositiva do chão (poesia quase toda), reunindo todos os livros publicados até o momento pelo poeta e suas entrevistas singularmente poéticas, suas entrevistas-poemas. Enquanto o título repetia o de um de seus livros ressaltando o "dicionário do ordinário" ali presente, o subtítulo apontava para uma poesia que, mesmo quantitativamente completa, será sempre "quase toda", trazendo uma espécie de incompletude ontológica (contrastando integralmente com o de "Poesia Completa" presente na penúltima e na última edições da Leya de 2010 e de 2013 de modo equivocado para atender à demanda do mercado. Estas últimas edições, diga-se, ainda retiraram, de modo incompreensível, talvez também por questões de mercado, as entrevistas do livro).

Exatamente sobre esse assunto, abordado logo na primeira pergunta que lhe fiz na entrevista com ele publicada em 1994, ele disse: "Trato com muito carinho o que me falta. E hoje só me falta o começo e o resto. Sou freguês da incompletude. Não sei até quando irei a me arrastar por pedaços de mim perdidos. Poesia quase toda há de ser até quando". A falta, por todos os lados nessa frase, inclusive no "até quando" da dimensão supostamente temporal, é uma das características principais que perpassam o caminho dessa poesia como um de seus pensamentos constantes, como pode ser lido em diversas passagens, como em um verso final de um poema de O livro das ignorãças a respeito de Bernardo da Mata: "(Pode um homem enriquecer a natureza com a sua incompletude?)". Tal enriquecimento da natureza pela incompletude de um homem oferece uma nova leitura ao verso mencionado do poema do estafermo, que, dizendo "O que um poeta falta para árvore" poderia também significar "O que um poeta falta para [a] árvore", ou seja, à árvore faltaria exatamente a incompletude que o poeta lhe daria.

Recordo-me bem do lançamento, em 1990, na Livraria Dazibao, de Ipanema, de Gramática expositiva do chão (poesia quase toda). A livraria era pequena e, enquanto eu estava lá, a presença era constitutivamente de familiares e amigos próximos. Leitores desconhecidos, como eu, se havia, eram poucos, quase nenhuns. Quando chegou a minha vez de lhe pedir a dedicatória, eu the disse: "Manoel, gostaria de lhe dizer duas coisas: primeiro, agradecer você pela sua poesia; e lhe dizer que não consigo ler seus poemas sem rir". Foi o suficiente para criar um vínculo afetivo com a generosidade que lhe é característica. Depois de, por conta de meu modo de agradecimento, ter dito que eu certamente era um poeta, me passou o telefone do apartamento que ele tinha no Leblon, dizen- 
do para eu ligar para ele nos próximos dias para uma visita. Poucos dias depois, telefonei mesmo para ele e agendamos a visita imediata.

Nela, o assunto do riso voltou à tona quando lhe disse que, para mim, leitor assíduo e admirativo de João Cabral, descobri nele um trabalho de linguagem tão intenso quanto o do poeta pernambucano, mas que, por uma direção inteiramente distinta, abria todo um novo campo de possibilidades e respiração para a poesia. Foi quando ele me disse, rindo: "A diferença entre mim e Cabral é que ele não sabe rir". Quando poucos anos depois, na entrevista mencionada realizada por mim cujas perguntas the foram enviadas em fins de 1992 e as respostas me chegaram por escrito em 10.5.1993, feita por escrito, intitulada $A s$ coisas que não existem são mais bonitas, perguntei a ele sobre suas brincadeiras sintáticas, dizendo-lhe, mais uma vez, que não conseguia ler seus poemas sem rir, ele me respondeu:

Não consigo escrever poesia à vera. Só sei jogar à brinca em poesia. Fazer o inútil de-sério cheira a necedade. É através do riso que a inocência se plena. É tão idiota o solene que tenho sempre vontade de constar nele um cago. Igual que fizesse o Carlitos esfregando uma torta na cara de intendente. Pegar no espaço termos subjacentes pra juntá-los nas frases, não será o mesmo que pegar moscas no hospício para dar banho nelas? Depois de deixar as moscas bem úmidas como se fossem uma flor?

Tal passagem em que diz que o solene é tão idiota que ele sempre tem vontade de constar nele um cago compareceu em seguida no poema XV de $O$ livro das ignorãças: "Aos blocos semânticos dar equilíbrio. Onde o / abstrato entre, amarre com arame. Ao lado de um primal deixe um termo erudito. Aplique na / aridez intumescências. Encoste um cago ao / sublime. E no solene um pênis sujo". Em uma das cartas enviadas para mim, em 24.12.1996, ao saber que eu havia participado do jurado (aliás, juntamente com meu anfitrião Antonio Carlos Secchin) do Prêmio Alfonso Guimarães, da Biblioteca Nacional, que considerou O livro das ignorãças o melhor do respectivo ano em poesia, ele me escreveu:

Foi bom saber que você estava entre os votantes. Bem sei do seu gosto apaixonado por minhas brincadeiras com as palavras. Desde quando o conheci - me lembro -, você se agachou e disse em meu ouvido "rio muito quando leio seus versos". Em que mais pode alguém acreditar senão no riso? Que elogio pode um poeta desejar senão de estar brincando com as palavras. De fazer graça com elas. Meu Deus, tenho medo de ser conspícuo. Tenho medo de ser solene. Tenho medo de ser responsável. Tenho que ser irresponsável para escrever o sério que se quebra no riso.

Ainda sobre a minha relação com a poesia de Manoel de Barros pelo riso, não tenho como me esquecer de um fato ocorrido comigo mesmo em um jantar, que acabou por virar um pequeno texto que, por suas características, foi publicado tanto em um livro de ensaios quanto em minha poesia reunida, ambos 
de 2007. Conto o biograficamente ocorrido pelo breve poema-crítico em prosa, intitulado "Manoel de Barros":

Recém-chegado ao jantar, de fraque branco encardido, dizia-se: Deus. Indubitáveis, os sinais - a roupa, o ígneo cabelo em desalinho, a barba por fazer, a Bíblia de cor e salteada, o sebastianismo com seus mistérios... E não parava por aí... Que cada um fizesse uma pergunta. E fizeram - as maiores: Por que o sofrimento humano?; O que é a verdade?; E a felicidade?; Como recebê-Lo no coração?... A todas, eloquentemente, respondia. Sem dar-me chance, obrigava-me à pergunta. Apropriei-me, por fim, do poeta: Por que a quinze metros do arco-íris o Sol é cheiroso? Eis que Deus mediu distância, umidade, calor... Emputeceu-se: Essa não vale, isso é sacanagem comigo! Pois é, meu caro, poesia que é poesia desbanca até Deus.

Volto assim com a pergunta do poeta: "Em que mais pode alguém acreditar senão no riso?”. A última carta que recebi de Manoel de Barros é uma resposta ao meu envio a ele do ensaio, "Do esbarro entre poesia e pensamento: uma aproximação à poética de Manoel de Barros", escrito para minha tese de doutorado, defendida em 1999, que teve, entre outros, o poeta, professor, crítico, amigo e hoje "acadêmico" Antonio Carlos Secchin na banca, dando-me a alegria de sua presença. Antes de tal ensaio, eu havia publicado uma resenha do Livro sobre nada, em 1997, na revista Poesia Sempre, cujo editor era, mais uma vez, Antonio Carlos Secchin. Presente no livro Pelo colorido, para além do cinzento (a literatura e seus entornos interventivos), "Do esbarro entre poesia e pensamento: uma aproximação à poética de Manoel de Barros" foi publicado pela Azougue Editorial/Faperj em 2007. Na carta de 20.5.2002, o poeta me escrevia: "Recebi e li com gosto o seu trabalho Do esbarro entre poesia e pensamento. Achei magistral sua leitura. Magistral de mestre mesmo. [...] Seu trabalho é dos melhores presentes que minha poesia já recebeu”. Essa carta é, sem dúvidas, um dos maiores presentes que minha escrita crítica já recebeu. Há muito, por pudor, não escrevo para ele, tão somente por, como diz o último verso do primeiro poema de Face imóvel, seu Segundo livro, “[...] eu não vou perturbar a paz que ele depôs na praça, quieto”. Não, eu não iria mais perturbar a paz desse homem que ainda teria tanto a escrever e sempre se recolhera no afastamento dos grandes centros.

\section{Notas}

1 Conferência proferida na ABL, em 22 de julho de 2014.

2 Em outros livros, ainda aparecerão o bugre Aniceto, Aristeu, o canoeiro Apuleio (Seo Adejunto), Bugre Felisdônio, Ignácio Rayzama, Rogaciano, Malafincado, Sombra-Boa, Andaleço (o Homem do Saco), Mano Preto, Catre-Velho, o avô do poeta, Mário-pega-sapo, Seo Antônio Ninguém, Bola-Sete, Maria Pelego Preto. 
RESUMO - A poesia de Manoel de Barros toma como uma de suas forças "esses começos de coisas/ indistinta". Ao dizer que queria apenas se ser nas coisas, ele designa o poeta enquanto "o aparelho de ser inútil”, alguém que, através de um trabalho de desregramento do corpo, criando “inutensílios”, é colocado em fusão com as coisas e em desobediência intensiva dos sentidos da língua. Esta desobediência atua diretamente na reconstrução material da frase que, perturbando a ordem, busca dizer o inominado, o larval, os ínfimos das coisas, as pré- ou antecoisas e o inominado da linguagem.

Palavras-ChaVe: Manoel de Barros, Poesia, Aparelho de ser inútil, Inutensílio, Riso.

ABSTRACT-One of sources from which Manoel de Barros' poetry draws its strength are "these beginnings of things / indistinct". In saying that he merely wanted to be in things, he designates the poet as "a device for being useless", someone who, through the derangement of the body and by creating "inutensílios" [useless utensils], is led to fuse with things and to an intensive disobedience of the senses of language. This disobedience bears directly upon the physical reconstruction of the phrase - which, by disturbing the order, seeks to articulate the unnamed, the larval, the lowermost and undermost of things, the pre- or ante-things, and the unnameableness of language.

KEYWORDS: Manoel de Barros, Poetry, Device for being useless, "Inutensílio”, Laughter.

Alberto Pucheu, poeta, é professor de Teoria Literária da Faculdade de Letras da Universidade Federal do Rio de Janeiro (UFRJ). Cientista do Nosso Estado pela Faperj e pesquisador do CNPq. @- apucheu@gmail.com

Recebido em 30.10.2014 e aceito em 25.11.2014.

I Faculdade de Letra, Universidade Federal do Rio de Janeiro, Rio de Janeiro/Rio de Janeiro, Brasil. 
